\title{
Preoperative evaluation of ovarian masses with color Doppler and its correlation with pathological finding
}

\author{
Isha Khurana ${ }^{1}$, Meena N. Satia ${ }^{2}$ \\ ${ }^{1}$ Institute of Reproductive Medicine and IVF Centre, Primus Super speciality Hospital, 2 Chandragupta road, New \\ Delhi, India \\ ${ }^{2}$ Department of Obstetrics and Gynaecology, Seth Gordhandas Sunderdas Medical College and King Edward VII \\ Memorial Hospital, Mumbai, Maharashtra, India
}

Received: 30 May 2016

Revised: 09 June 2016

Accepted: 13 June 2016

\section{*Correspondence:}

Dr. Isha Khurana,

E-mail: ishakhurana83@yahoo.com

Copyright: $\odot$ the author(s), publisher and licensee Medip Academy. This is an open-access article distributed under the terms of the Creative Commons Attribution Non-Commercial License, which permits unrestricted non-commercial use, distribution, and reproduction in any medium, provided the original work is properly cited.

\section{ABSTRACT}

Background: Most ovarian cancers are diagnosed in advanced stages because these tumours may not cause any specific symptoms, particularly in its early stages. Though specific risk actors have been identified there are no reliable screening tests for ovarian cancer. However, improvements in identification of women at high risk for ovarian cancer, as well as improved imaging techniques like the USG and color Doppler along with CT Scan and MRI has increased the likelihood of early detection.

Methods: The aim of the study was to evaluate the efficacy of color and spectral Doppler in diagnosing the ovarian malignancy. A Prospective randomised study was conducted at a tertiary care centre where 50 patients with ovarian masses were selected. The study design included thorough history taking and clinical examination followed by evaluation of tumour markers. USG along with color Doppler evaluation was done followed by surgery and then corelated with histopathology. The color Doppler parameters such as vascularity, distribution of vascularity, pulsatility and resistive index were also evaluated and statistical significance assessed.

Results: Color Doppler showed increased vascularity in $100 \%$ of malignant tumors in contrast to only $54.24 \%$ of benign tumors. Absent blood flow in a solid tumor almost always ruled out the possibility of malignancy. Spectral Doppler helped to assess the nature of the blood vessels picked up on color Doppler. All the patients in the malignant group and 4 patients in the borderline group had PI $<1.0$. Remaining 6 tumors with $\mathrm{P} 1<1.0$ belonged to the benign group. Out of 15 patients with PI $>1.0,13$ were benign and 2 patients had borderline tumours. RI of $<0.4$ was seen in 8 Patients with malignancy and RI of $>0.4$ was seen in 26 patients with benign lesions.

Conclusions: Color Doppler is a good non-invasive modality to differentiate benign from malignant lesions. Vascularity is most sensitive and RI is most specific. Thus, color Doppler and spectral Doppler tremendously increased the reliability in diagnosing a malignant ovarian tumor. Color Doppler served as an important tool to rule out malignancy in solid tumors if they failed to show any intra-tumoral vascularity. B-Mode USG in combination with color Doppler and spectral Doppler is proposed as the first and foremost diagnostic modality in patients with ovarian tumor, so as to establish the definite diagnosis of malignancy early in the course of the disease.

Keywords: Color Doppler, Ovarian malignancy, Adnexal masses, Pulsatility index, Resistive index 


\section{INTRODUCTION}

The diagnosis of ovarian tumors remains a common clinical gynecologic problem. The early and definite diagnosis of ovarian malignancy is of grave clinical importance because prognosis depends totally on early diagnosis Ovarian tumors are the second most common malignancy of the genital system and are the most common cause of death from malignancy due to late diagnosis. The death rate from ovarian cancer far exceeds that of cervical and endometrial carcinoma combined. ${ }^{1,2}$ Thus discrimination between malignant and benign masses is crucial as well as challenging because of the high fatality rates and atypical presentations. ${ }^{3}$

Table 1: The international ovarian tumor analysis (IOTA) rules.

\begin{tabular}{|ll|}
\hline B Rules & M-Rules \\
\hline Unilocular cysts & Multilocular cysts \\
\hline $\begin{array}{l}\text { Presence of solid } \\
\text { components where the } \\
\text { largest solid component } \\
\text { is less than } 7 \text { cms }\end{array}$ & Irregular solid tumours \\
\hline $\begin{array}{l}\text { Presence of acoustic } \\
\text { shadowing }\end{array}$ & Ascites \\
\hline $\begin{array}{l}\text { Smooth multilocular } \\
\text { tumour with a largest } \\
\text { diameter less than 100 } \\
\text { mm }\end{array}$ & $\begin{array}{l}\text { At least four papillary } \\
\text { structures irregular } \\
\text { multilocular solid tumour } \\
\text { with largest diameter } \geq 100 \\
\text { mm }\end{array}$ \\
\hline $\begin{array}{l}\text { No blood flow in duplex } \\
\text { Doppler }\end{array}$ & $\begin{array}{l}\text { At least four papillary } \\
\text { structures irregular } \\
\text { multilocular solid tumour } \\
\text { with largest diameter } \geq 100 \\
\text { mm }\end{array}$ \\
\hline $\begin{array}{l}\text { If one or more M features were present in the } \\
\text { absence of B feature- Malignant }\end{array}$ \\
$\begin{array}{l}\text { If one or more B features were present in the absence } \\
\text { of an M features- Benign }\end{array}$ \\
\hline $\begin{array}{l}\text { If both M features and B features were present, or if } \\
\text { none of the features was present- inconclusive }\end{array}$ \\
\hline
\end{tabular}

Recently the role of color and spectral Doppler in the diagnosis of ovarian malignancy has been a subject of enormous debate with varying opinions on the efficacy of color and spectral Doppler. ${ }^{4}$ Because population-based screening is not currently approved by the ACOG. ${ }^{5}$ Incidental or symptomatic adnexal masses should be examined thoroughly for the presence of malignancy. Various scoring systems, mathematical models, and software programs, which were based on sonographic findings, were proposed for better discrimination of malignant ovarian tumors. The most widely used of these predictive systems is the risk of malignancy index (RMI) proposed by Jacobs et al. ${ }^{6}$ The RMI is a simple scoring system incorporating basic sonographic parameters, serum cancer antigen 125 (CA-125) levels, and menopausal status. Sonography is a useful tool for determination of malignancy, and nearly precise diagnosis with sensitivity of greater than $95 \%$ and specificity of approximately $90 \%$ for malignancy is possible in experienced hands. ${ }^{7,8}$ However, in settings with less experienced sonographers, standardized techniques, definitions, and values are necessary. In an effort to achieve this, the International Ovarian Tumor Analysis (IOTA) group gave clear definitions and measurements to describe the sonographic features of adnexal tumors (Table 1). ${ }^{9}$

The simple rules yielded conclusive result 95\% sensitivity and a specificity of $96 \%$.

\section{Aims and objectives}

Pre-operative evaluation of ovarian masses with Color Doppler flow imaging and its correlation with intraoperative and histopathological findings, to assess the diagnostic reliability of Doppler sonography findings to differentiate malignant and benign ovarian masses.

\section{METHODS}

This study involves observational longitudinal prospective analysis of fifty non-consecutive patients admitted in gynecology ward of tertiary care hospital for a period of 2 years, for evaluation and operative intervention for ovarian masses. Patients of infective pathology and other adnexal masses were excluded. After enrollment Detailed history taking including age, symptoms, menstrual history, family history of ovarian cancer was sought, General and pelvic examination and Blood investigations were done followed by Transvaginal gray-scale sonography and color Doppler sonography-parameters assessed included Maximum tumor volume, locularity, gray scale morphology, presence or absence of papillary projections/solid areas echogenicity, ascites, presence of vascularity, distribution of vascularity, morphology of flows, resistance index (RI), pulsatility index (PI), highest peak systolic velocity (PSV), morphological index (MI) using DePriest morphological scoring system. ${ }^{10}$ Tumor marker and computerized tomography and MRI examination (wherever required) was also done. All patients underwent operative procedure (laparoscopy and laparotomy) specimen was sent for histopathology.

\section{Scanning procedure}

All women were scanned trans abdominally and transvaginally with real time gray scale ultrasound examination followed by color Doppler sonography. The location of the tumor was recorded as unilateral/ bilateral, tumour volume, septal thickness, papillary projections were looked for. The echogenicity of the tumor was defined as solid if solid tissue constituted at least $80 \%$ of the tumor and as cystic if solid tissue constituted less than $80 \%$. If any solid component was noted within the cystic lesion, the percentage of the solid tissue was calculated. 
Subsequently, the percentage of the solid component was calculated by the formula (volume of the solid component/volume of the tumor $) \times 100$. After standard gray mode morphological examination the entire tumor was surveyed by color Doppler Sonography and presence of vascularity assessed, if no blood flow was detected after 10 minutes of scanning, the tumor was considered to have no flow. When blood flow was detected within the septa it was characterized as septal, in solid tumor areas, it was categorized as central, whereas when blood flow was localized in the cyst wall, it was categorized as peripheral.

In the areas of flow detected, the pulsed Doppler mode was activated, and flow velocity waveforms were obtained .The peak systolic velocity (PSV, centimeters per second), pulsatility index (PI), and Resistive index (RI) were electronically calculated from the waveforms.

$\mathrm{PI}=$ peak systolic flow - end-diastolic flow mean systolic flow

RI = peak systolic flow - end-diastolic flow Peak systolic flow

At least 2 readings were taken for each vessel and the lowest value was used for statistical analysis. A PI $<1.0$ or RI $<0.4$ was considered suggestive of malignancy.

\section{Histopathology}

Specimen obtained at surgery was mounted on blocks and one section per centimeter was taken for examinations by pathologist tumor were classified in accordance with the system recommended by World Health Organization. FIGO staging was done On basis of the their tumor potential they were broadly divided into 'benign', 'malignant' and 'borderline' for the purpose of further analysis.

\section{RESULTS}

The various parameters of Doppler sonography were then analysed with respect to the three groups (based on histopathology) namely: (A) Benign (B) Borderline (C) Malignant.

A total of 50 patients were enrolled in the study. The number of patients under each category following histopathological analysis is shown in Figure 1.

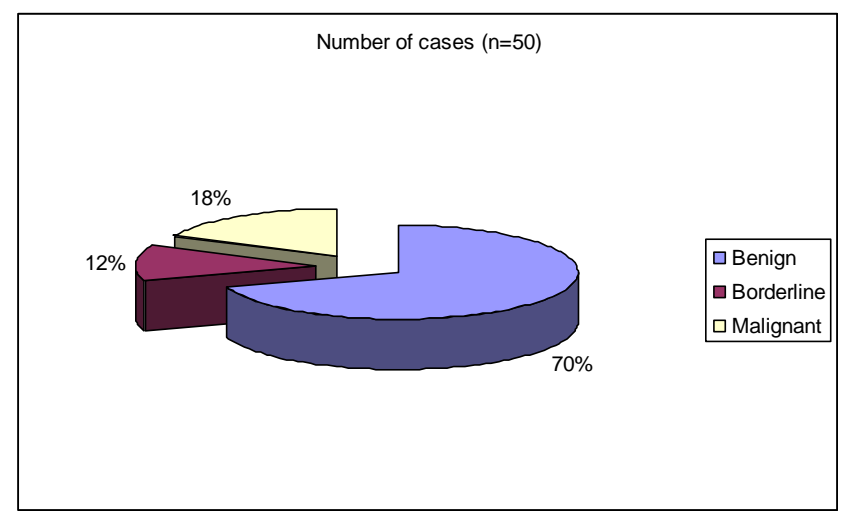

Figure 1: Distribution of cases in study population.

\section{Demographic profile}

\section{Age distribution}

The mean age were $37.32 \pm 12.85$ years ranging from 17 years to 75 years. The mean age in the benign group was $33.29 \pm 11.24$ years, $45.50 \pm 5.43$ years in the borderline group and $47.56 \pm 14.71$ years in the malignant group. The difference in age in between the three groups was statistically significant $(\mathrm{p}=0.004)$.

Table 2: Age group distribution of the cases of the three groups.

\begin{tabular}{|lllllll|}
\hline & Age group & & & & & Total \\
\hline & $\leq 25$ years & $26-35$ years & $36-45$ years & $46-55$ years & >55 years & \\
\hline Benign & $9(25.7 \%)$ & $15(42.9 \%)$ & $5(14.3 \%)$ & $4(11.4 \%)$ & $2(5.7 \%)$ & 35 \\
\hline Borderline & 0 & 0 & $3(50 \%)$ & $3(50 \%)$ & 0 & 6 \\
\hline Malignant & $1(11.2 \%)$ & 0 & $2(22.2 \%)$ & $3(33.3 \%)$ & $3(33.3 \%)$ & 9 \\
\hline
\end{tabular}

\section{CA-125}

CA 125 estimation was done as it is one of the established method which aids in differentiation of ovarian masses pre-operatively. However for statistical analysis CA-125 was the only considered as it done for all the patients under study. The cut-off value over which the mass was considered as malignant was $\geq 35 \mathrm{IU} / \mathrm{ml}$. The mean value of CA-125 in the benign group was $17.68 \pm 13.41 \mathrm{IU} / \mathrm{ml}, 23.09 \pm 19.80 \mathrm{IU} / \mathrm{ml}$ in the borderline group and $528.44 \pm 111.83 \mathrm{IU} / \mathrm{ml}$ in the malignant group. The difference in between the three groups was statistically significant $(\mathrm{p}=0.001)$.

However, when the subgroup analysis was done the data was significant in between benign and malignant groups (p value 0.001 ). It was also noted that $80 \%$ of patients in study had CA-125<35 IU/ml, rest had levels $>35 \mathrm{IU} / \mathrm{ml}$. 


\section{Gray scale morphology}

The tumour masses are classified into solid, solid-cystic and cystic based on gray scale morphology. On one hand $71.4 \%$ of the benign tumours were cystic, on the other all the borderline tumours and 7 of the 9 malignant tumours were solid cystic on gray scale morphology. The data with respect to gray scale morphology was statically significant ( $p$ value 0.002 ). In this study only one benign tumour was noted to have solid consistency (Table 3).

\section{Papillary projections}

$60 \%$ of all tumours exhibited papillary projections on transvaginal sonography. All the malignant neoplasms and 5 of six borderline variety belonged to the above mentioned group. In the benign group 16 tumours exhibited papillary projections, while in remaining 19 tumours papillary projections were absent. The data was statistically significant at the $\mathrm{p}$ value 0.006 . The subgroup analysis revealed that the data was significant in between benign and malignant groups with $\mathrm{p}$ value 0.003 (Table 3).

Table 3: Gray scale morphology characteristics of tumours including papillary projections.

\begin{tabular}{|llll|l|}
\hline Gray scale morphology & Benign & Borderline & Malignant & Total $(\mathrm{n}=50)$ \\
\hline Cystic & $25(71.4 \%)$ & 0 & 2 & 27 \\
\hline Solid-cystic & 9 & $6(100 \%)$ & $7(77.8 \%)$ & 22 \\
\hline Solid & 1 & 0 & 0 & $1 \mathrm{p}$ value 0.002 \\
\hline Papillary projections & & & & \\
\hline Absent & 19 & 1 & 0 & 20 \\
\hline Present & 16 & 5 & 9 & $30 \mathrm{p}$ value 0.006 \\
\hline
\end{tabular}

\section{Color Doppler ultrasound}

Doppler parameters were optimized for detection of flow and calculation of impedance indices. Flow results were documented as being absent or present. The vessel location was also noted. On spectral Doppler, the lowest resistive index $(\mathrm{RI})$ and pulsatility index $(\mathrm{PI})$ detected at any point in the mass were used for analysis. However, the third variable maximum peak systolic velocity was recorded for a limited number of patients, so it was not included for analysis. The Doppler findings were considered as being suggestive of malignancy when RI $<0.4$ and PI $<1.0$

\section{Vascularity}

In this study, 34 tumours were found to be vascular. This included all the malignant and borderline neoplasms and 19 benign neoplasms. None of the malignant and borderline tumours were found to be avascular. However, for statistical calculations the borderline group was clubbed with the malignant group. When the data in between the two groups was analysed it was found to be highly significant at the $\mathrm{p}$ value of 0.001 (Table 4).

Table 4: Presence/absence of flow of blood in tumors.

\begin{tabular}{|llll|l|}
\hline Vascularity & Benign & Borderline & Malignant & Total \\
\hline Present & $19(54.3 \%)$ & $6(100 \%)$ & $9(100 \%)$ & 34 \\
\hline Absent & 16 & 0 & 0 & $16(\mathrm{p}$ value 0.001$)$ \\
\hline
\end{tabular}

It was noted that $58.82 \%$ of vascular tumours had peripheral vascular distribution. However, central vascular distribution was noted in one benign neoplasm and one malignant tumour (with septal vascular distribution). 11 of 15 malignant tumours had peripheral blood supply.

\section{Resistive index}

The value of $\mathrm{RI}<0.4$ was considered as an indicator of malignant lesion. In this study, the RI was $<0.4$ in 6 patients of the malignant group and 1 patient of the borderline group. Only 1 patient of benign group had
$\mathrm{RI}>0.4$. But 3 patients of malignant group and 5 patients of the borderline group had RI $>0.4$. The data for RI was statistically significant in between the three groups ( $\mathrm{p}$ 0.002) (Table 5).

Table 5: Resistive index in the tumor groups.

\begin{tabular}{|lllll|} 
RI & Benign & Borderline & Malignant & Total \\
$<0.4$ & 1 & 1 & 6 & 8 \\
\hline$\geq 0.4$ & 18 & 5 & 3 & $\begin{array}{l}26 \\
(\mathrm{p} \text { value } \\
\end{array}$ \\
& & & & $0.002)$
\end{tabular}


For statistical evaluation the borderline tumour group was combined with the malignant group and data was analysed. The mean RI in the benign group was $0.52 \pm 0.16$. The mean $\mathrm{RI}$ in the malignant group was $0.39 \pm 0.12$. The difference in RI in between the two groups was statistically significant ( $p$ value 0.005 ) (Table 6).

Table 6: RI values in the two tumour groups.

\begin{tabular}{|lll|}
\hline RI & Benign & Malignant \\
\hline Mean with standard deviation & $0.52 \pm 0.16$ & $0.39 \pm 0.12$ \\
\hline Minimum & 0.42 & 0.20 \\
\hline Maximum & 0.70 & 0.60 \\
\hline
\end{tabular}

\section{Pulsatility index}

The value of PI <1.0 was considered as an indicator of malignant lesion. All the patients in the malignant group and 4 patients in the borderline group had $\mathrm{PI}<1.0$. Remaining 6 tumours with $\mathrm{P} 1<1.0$ belonged to the benign group. Out of 15 patients with PI>1.0, 13 were of benign group and 2 patients belonged to the borderline group. The $\mathrm{p}$ value of 0.003 suggested statistical significance for $\mathrm{P} 1$ in between the groups (Table 7).

Table 7: Pulsatility index in the tumor groups.

\begin{tabular}{|lllll|}
\hline PI & Benign & Borderline & Malignant & Total \\
\hline$<01.0$ & 6 & 4 & 9 & 19 \\
\hline \multirow{2}{*}{1.0} & \multirow{2}{*}{13} & 2 & 0 & $15(\mathrm{p}$ \\
& & & $0.003)$ \\
\hline
\end{tabular}

For statistical evaluation the borderline tumour group was combined with the malignant group and data was analysed. The mean PI in the benign group was $0.98 \pm 0.28$. The mean PI in the malignant group was $0.75 \pm 0.17$. The difference in PI in between the two groups was significant (p value 0.002) (Table 8).

Table 8: PI values in the two tumour groups.

\begin{tabular}{|lll|}
\hline PI & $\begin{array}{l}\text { Benign } \\
(\text { Mean } \pm \text { SD) }\end{array}$ & $\begin{array}{l}\text { Malignant } \\
(\text { Mean } \pm \text { SD) }\end{array}$ \\
\hline $\begin{array}{l}\text { Mean with standard } \\
\text { deviation }\end{array}$ & $0.98 \pm 0.28$ & $0.75 \pm 0.17$ \\
\hline Minimum & 0.9 & 0.45 \\
\hline Maximum & 1.40 & 0.99 \\
\hline
\end{tabular}

Table 9: Spearman coefficient of correlation between CA-125, RI \& PI.

\begin{tabular}{|lllll|}
\hline Parameters & CA-125 & R1 & PI & Total $(\mathrm{n}=50)$ \\
\hline CA-125 & 1 & 0.014 & 0.055 & 17 \\
\hline R1 & 0.014 & 1 & 0.896 & $31(62 \%)$ \\
\hline PI & 0.055 & 0.896 & 1 & $\begin{array}{l}2 \text { p value } \\
0.167\end{array}$ \\
\hline
\end{tabular}

Correlation was then studied in between the three parameters CA-125, RI and PI. Positive correlation was noted in between the three variables which were statistically significant at $\mathrm{p}$ value of 0.01 (Table 9).

\section{DISCUSSION}

There have been numerous studies in the world literature evaluating the role of color Doppler to distinguish between benign and malignant ovarian neoplasms, but the results have been conflicting. The present study evaluates the role of color Doppler sonography in pre-operative evaluation of ovarian masses and its correlation with histopathology. In addition, we also assessed the efficacy of CA-125 serum concentration estimation and transvaginal B mode ultrasonography in differentiating malignant and benign ovarian tumors. We however, have excluded patients with advanced disease to avoid bias and this explains the absence of such a group in our study.

\section{Demographic profile}

Our study included 50 patients from the age ranging between 17 to 75 years. Age is the most important independent risk factor for ovarian cancer in the general population Thus, adnexal masses in postmenopausal women are more likely to be malignant than those in premenopausal women. In our study also, we noted that the risk of malignancy increased with increasing age. Also, it was seen that in the benign group $68.6 \%$ of patients were less than 35 years of age. It was also seen that amongst the 9 postmenopausal females 4 had malignancy.

\section{Gray scale ultrasound}

In asymptomatic women with pelvic masses, transvaginal ultrasonography is the imaging modality of choice which has been widely used lately to study size and morphology of ovarian tumors for predicting malignant nature. Sensitivity ranging from $60 \%$ to $95 \%$ and specificity of $65-95 \%$ has been reported. ${ }^{19}$ It was only after the IOTA study that the clear definitions of ultrasonography parameters were formulated and these were used in subsequent studies. ${ }^{9}$ In our study we also same definitions of various morphological parameters have been used to validate comparison. We followed the De Priest Ultrasound score to predict malignancy. ${ }^{10}$ The morphological score of a mass $\geq 5$ was considered as malignant. In this study we found that most of the benign tumors $(\mathrm{n}=25)$ measured $<10 \mathrm{cms}$. This measurement was more than $5 \mathrm{cms}$ for the malignant group (p value 0.018 ). This was in accordance to the data reported by Tailor et al20 in which benign lesions had mean diameter of $6.98 \mathrm{cms}$ and malignant lesions measured $9.81 \mathrm{cms}(\mathrm{p}$ value 0.013 ). In the present study, most of the benign lesions were unilocular $(77.1 \%)$ and all the borderline lesions and most of the malignant lesions were multilocular (77.8\%) (p value 0.000). Tailor et al reported that $67.3 \%$ of the benign tumors and $46.7 \%$ of the 
malignant lesions were unilocular. ${ }^{20}$ Similarly, Kobal B et al reported $31.8 \%$ of benign lesions and $62.5 \%$ malignant lesions were multilocular. ${ }^{23}$ Thus the present study and other studies mentioned above suggest that the malignant lesions are predominantly multilocular. The gray scale morphology in our sample size revealed that $71.4 \%$ of the benign tumors were cystic. However, all the borderline tumors and 7 of 9 malignant tumors were solid cystic.

\section{Papillary projections}

One of the most consistent findings seen in various studies was presence of papillary projections and their correlation with malignant potential of ovarian mass. The consistency of this parameter in predicting malignancy has provided it place in the various morphological scoring systems. In this study, $60 \%$ of all tumors exhibited papillary projections on transvaginal sonography. All the malignant neoplasms and 5 of six borderline variety belonged to the above mentioned group. In the benign group 16 tumors exhibited papillary projections, while in remaining 19 tumors papillary projections were absent ( $\mathrm{p}$ value 0.006 ). The papillary projections as a predictor of malignancy had very high sensitivity of $93.33 \%$ but lower specificity (54.29\%). Tailor et al reported the presence of papillary projections in $9.6 \%$ of benign lesions and in $73.3 \%$ of malignant lesions. This similar pattern was also noted by Kobal B et al23 in their study. L Valentin et al noted papillary projections in $64 \%, 67 \%$ and $41 \%$ cases in the borderline group, patients with epithelial cancer stage-I and patient with epithelial cancer stage-IV respectively ( $\mathrm{p}$ value $0.0034) .^{23,24}$

\section{Morphological scoring system}

De Priest morphological ultrasound score was used to predict malignancy. ${ }^{10}$ The morphological score of a mass $\geq 5$ was considered as malignant. The sensitivity, specificity, positive predictive value and negative predictive value in the present study were $100 \%, 48.57 \%$, $45.45 \%$ and $100 \%$. The results of our study are comparable to those reported by De Priest et al in their original article. ${ }^{10}$ The mean value of $\mathrm{MI}$ for benign lesions was $4.89 \pm 2.20$ and $8.93 \pm 1.53$ for malignant lesions. As noted in various studies gray scale morphology has high sensitivity in diagnosing ovarian malignancy but low specificity. The similar results were noted in our study.

\section{Color Doppler sonography}

In this study, we found PI as a single parameter proved to be the better index for discrimination between benign and malignant ovarian tumors. At the cut-off of 1.0, sensitivity, specificity, positive predictive value and negative predictive values were $86.67 \%, 68.42 \%, 68.42 \%$ and $86.67 \%$ respectively. These values were better than those for RI at cut-off value 0.4. The sensitivity, specificity, positive predictive value and negative predictive values were $46.67 \%, 94.74 \%, 87.5 \%$ and $69.63 \%$ respectively. In spite of its high specificity, RI as a single parameter is less useful in the present study as it has very low sensitivity. Also as noted in other studies the mean values of RI and PI in this study for benign lesions were more than malignant lesions. The values of RI and PI were $0.52 \pm 0.16$ and $0.98 \pm 0.28$ for benign lesions and $0.39 \pm 0.12$ and $0.75 \pm 0.17$ for malignant lesions. The difference in data for RI and PI values in between the benign and malignant groups was statistically significant at $\mathrm{p}$ value of 0.005 and 0.002 respectively. As noted in other studies overlap between benign and malignant ovarian tumors for RI and PI values was also noted.

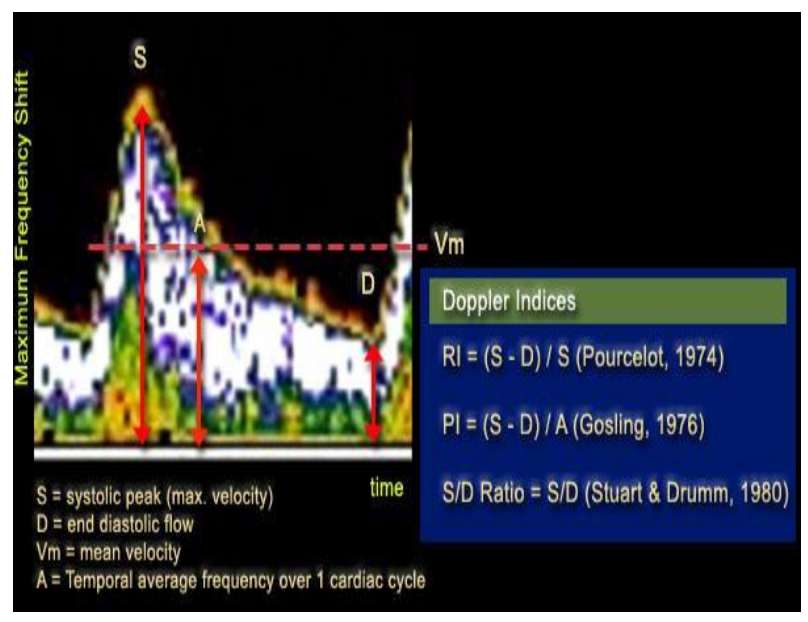

Figure 2: Doppler flow indices.

Angiogenesis and neovascularization in malignant tumors result in a high number of additional, atypical tumor vessels, which cause a decreased blood flow resistance. The resistivity index and pulsatility index of the Doppler waveform have been measured in ovarian tumors by several investigators. Some authors have suggested that color Doppler sonography is more sensitive and specific than transvaginal sonography alone. In our study cut off values of 0.4 and 0.1 for RI and PI respectively as the demarcation between benign and malignant for ovarian tumors was used.

\section{Vascularity}

Junasz B et al successfully demonstrated the presence of new vessels in the ovarian and endometrial cancers. ${ }^{25}$ In the present study out of 50 tumors, 34 tumors were vascular. This included all the malignant and borderline neoplasms and 19 benign neoplasms. None of the malignant and borderline tumors were found to be avascular. This data is in concordance with the findings of Timor-Tritsch and colleagues who have reported that lack of blood flow in an ovarian tumor as detected by color Doppler may preclude cancer. ${ }^{26}$ To further add on most of the studies in world literature have consistently detected blood flow in the malignant lesions, while some 
other workers believe that absence of vascularity does not always rule out malignancy.

Vascularity as a predictor of malignancy achieved sensitivity, specificity, positive predictive value and negative predictive value of $100 \%, 45.71 \%, 44.12 \%$ and
$100 \%$. The vascularity as a single parameter though supplements the ultrasound, but it does not increase the specificity obtained on ultrasound alone as shown in Table 10.

Table 10: Sensitivity, specificity, positive predictive value and negative predictive value of CA-125, transvaginal ultrasound (papillary projections (PP) and morphological index (MI)) and color Doppler ultrasonography (vascularity (V), RI and PI).

\begin{tabular}{|c|c|c|c|c|c|c|c|}
\hline \multicolumn{2}{|l|}{ Modality } & Sensitivity (\%) & Specificity (\%) & PPV (\%) & NPV (\%) & $\begin{array}{l}\text { False } \\
\text { Positive (\%) }\end{array}$ & $\begin{array}{l}\text { False Negative } \\
(\%)\end{array}$ \\
\hline \multicolumn{2}{|l|}{ CA-125 } & 46.67 & 91.43 & 70 & 80 & 53.33 & 8.57 \\
\hline \multirow{2}{*}{ TVS } & PP & 93.33 & 54.29 & 46.67 & 95 & 45.71 & 6.67 \\
\hline & MI & 100 & 48.57 & 45.45 & 100 & 51.43 & 0 \\
\hline \multirow{3}{*}{ CDS } & V & 100 & 45.71 & 44.12 & 100 & 54.29 & 0 \\
\hline & RI & 46.67 & 94.74 & 87.5 & 69.23 & 5.26 & 53.33 \\
\hline & PI & 86.67 & 68.42 & 68.42 & 86.67 & 31.58 & 13.33 \\
\hline
\end{tabular}

For the purpose of statistical analysis the borderline group was combined with the malignant group.

Table 11: Summary of important studies done in world literature.

\begin{tabular}{|c|c|c|c|c|}
\hline Study & Modality \& cases & Parameters & Results & Comments \\
\hline 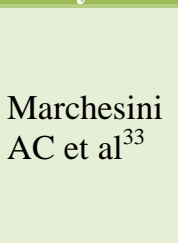 & $\begin{array}{l}\text { TVS \& CDS } \\
(\mathrm{n}=67, \mathrm{bl}-52, \mathrm{ml}- \\
15)\end{array}$ & $\begin{array}{l}\text { RI, PI, PSV. EDV in } \\
\text { two vessels } \\
\text { intraclass coefficient } \\
\text { of correlation (ICC) } \\
\text { was calculated for all } \\
\text { above }\end{array}$ & $\begin{array}{l}\text { RI: SE-84.6\%, SP-86.7\%, } \\
\text { ICC-0.60 } \\
\text { PI: SE-69.2\%, SP-93.3\%, } \\
\text { ICC-0.65 } \\
\text { TVS: SE-80\%, SP-65.4\% }\end{array}$ & $\begin{array}{l}\text { PSV and EDV present poor } \\
\text { intra-tumoral reliability. the } \\
\text { lower RI evaluated in at least } \\
\text { two distinct sites of the tumor, } \\
\text { was able to improve the } \\
\text { performance of grey scale }\end{array}$ \\
\hline $\begin{array}{l}\mathrm{R} \text { Madan et } \\
\mathrm{al}^{30}\end{array}$ & $\begin{array}{l}\text { TVS \& CDS } \\
(\mathrm{n}=74)\end{array}$ & $\begin{array}{l}\text { Morphologic } \\
\text { indexing, color flow } \\
\text { imaging, spectral } \\
\text { imaging \& HPE } \\
\text { correlation }\end{array}$ & $\begin{array}{l}\text { Sonomorphology highest } \\
\text { SE }(92.5 \%) \text { \& NPV } \\
(92.8 \%) \\
\text { Vessel morphology \& } \\
\text { arrangement highest SP } \\
(96.8 \%) \text { \& PPV (95.2\%) } \\
\text { PSV better than RI \& PI } \\
\text { Sonomorphologic+Vascular } \\
\text { scoring improved }\end{array}$ & $\begin{array}{l}\text { Considerable overlap in } \\
\text { morphologic scoring. Therefore } \\
\text { multiparameter analysis } \\
\text { incorporating morphologic } \\
\text { scoring, vessel location, vessel } \\
\text { arrangement and spectral } \\
\text { waveform }\end{array}$ \\
\hline 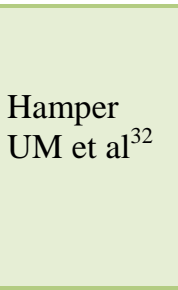 & $\begin{array}{l}\text { TAS, TVS, CDS } \\
\text { \& pathological } \\
\text { correlation } \\
(\mathrm{n}=31)\end{array}$ & RI, PI & $\begin{array}{l}\text { Benign lesions }(\mathrm{n}=25) \\
\text { RI:0.77 } \pm 0.22 \\
\text { PI: } 1.93 \pm 1.02 \\
\text { Malignant lesions }(\mathrm{n}=6) \\
\text { RI:0.5 } \pm 0.17 \\
\text { PI:0.77 } \pm 0.33\end{array}$ & $\begin{array}{l}\text { High PI \& RI indicate benign } \\
\text { adnexal processes }\end{array}$ \\
\hline $\begin{array}{l}\text { Fleischer } \\
\text { AC } \\
\text { et } \mathrm{al}^{31}\end{array}$ & $\begin{array}{l}\text { TAS, TVS, CDS } \\
\& \text { pathological } \\
\text { correlation } \\
(\mathrm{n}=62)\end{array}$ & $\begin{array}{l}\text { PI } \\
\text { PPV } \\
\text { NPV }\end{array}$ & $\begin{array}{l}\text { PI }<1.0 \text { for } \mathrm{ml} \\
\text { PPV: } 83 \% \& N P V: 98 \% \text { for } \\
\text { CSD }\end{array}$ & $\begin{array}{l}\text { CDS seems to be accurate } \\
\text { to exclude malignancy, however } \\
\text { misdiagnosis may occur in cases } \\
\text { of inflammatory \& metabolically } \\
\text { active benign masses }\end{array}$ \\
\hline
\end{tabular}

Tumor vessels can be grossly categorized as central or peripheral. ${ }^{27}$ Although this classification is somewhat misleading anatomically, it is helpful in describing the location of tumor vessels that are detectable with ultrasound. Peripheral tumor vessels are derived from pre-existing vessels in the affected region, whereas central vessels are newly formed in response to tumorelaborated angiogenic factors or intra-tumoral necrotic processes. Benign lesions are usually supplied by 
peripheral and pericystic vessels, while malignant tumors more often have a central type of vascular supply.

Ueland et al also concluded that morphological indexing is an accurate and inexpensive method to differentiate benign and malignant lesions and addition of color Doppler ultrasonography did not improve diagnostic accuracy of MI. ${ }^{22}$ Kurjak et al reported that the pattern of blood flow could also differentiate between the ovarian tumors. Peripheral bold flow is usually suggestive of benign tumors and central blood flow characterizes malignant tumor. ${ }^{28}$ Witczak $\mathrm{K}$ et al also stressed that central vessel localization was the single most significant attribute in tumor malignancy differentiation (with $\mathrm{p}$ value $<0.0001) .{ }^{29}$ However, our study showed contrasting results. Out of the 34 vascular tumors, 20 had peripheral blood supply. This included 12 benign tumors, 2 borderline tumors and 6 malignant tumors. This discrepancy is attributed to the fact that most of the malignant tumors were solid cystic $(n=7)$ which accounted for peripheral bold flow.

As evident from the above discussion and the values in Table 10 all the parameters are helpful in predicting the malignant potential of a tumor, but all of them have their own limitations when used alone.

\section{CONCLUSION}

This study shows that,

- Age is a statistically significant risk factor for occurrence of ovarian malignancy.

- Postmenopausal status was consistently found to carry increased risk of malignancy

- CA125 of $\geq 35 \mathrm{IU} / \mathrm{ml}$ was found to be indicative of malignant potential

- Grey scale morphology: tumor diameter $>10 \mathrm{cms,}$ tumor volume of $>500 \mathrm{~cm}^{3}$, multilocularity, solidcystic morphology, presence of papillary projections, mixed echogenicity, presence of ascites and DePriest morphological index of $\geq 5$ were indicative of malignant ovarian lesion.

- Color Doppler sonography: presence of vascularity, RI $<0.4$ PI $>1$ were found to corroborative with malignancy. Vascularity and PI are more sensitive parameters while RI is more specific.

- Conservative surgery was preferred modality of treatment in benign lesions while extensive radical surgeries were done for malignant lesions.

As per this study we recommend that initial clinical pelvic examination should be done thoroughly, as it is an art which cannot be replaced by a sophisticated diagnostic gadget. This should be supplemented by transvaginal sonography as an initial diagnostic tool to predict malignancy in ovarian mass. The addition of Doppler for cases in which sonography findings are inconclusive can be helpful, this will save both time and cost. Doppler sonography when used by experienced examiners provides significant additional diagnostic information that can confirm a tentative diagnosis based on morphological criterion and would seem prudent in management decisions.

\section{Funding: No funding sources}

Conflict of interest: None declared

Ethical approval: The study was approved by the Institutional Ethics Committee

\section{REFERENCES}

1. American College of Obstetricians and Gynecologists. ACOG Committee Opinion: the role of the generalist obstetrician-gynecologist in the early detection of ovarian cancer. Obstet Gynecol. 2002;100:1413-6.

2. Salzberg M, Thurlimann B, Bonnefois H, Fink D, Senn H. Current concepts of treatment strategies in advanced or recurrent ovarian cancer. Oncol. 2005;68(4-6):293-8.

3. Manjunath AP, Pratapkumar, Sujatha K, Vani R. Comparison of three risk of malignancy indices in evaluation of pelvic masses. Gynecol Oncol. 2001;81:225-9.

4. Yuen PM, Yu KM, Yip SK, Lau WC, Rogers MS, Chang A. A randomized prospective study of laparoscopy and laparotomy in the management of benign ovarian masses. Am J Obstet Gynecol. 1997;177:109-14.

5. Committee on Gynecologic Practice, American College of Obstetricians and Gynecologists. ACOG committee opinion: routine cancer screening. Number 185, September 1997 (replaces no. 128, October 1993). Int J Gynaecol Obstet. 1997;59:15761.

6. Jacobs I, Oram D, Fairbanks J, Turner J, Frost C, Grudzinskas JG. A risk of malignancy index incorporating CA 125, ultrasound and menopausal status for the accurate preoperative diagnosis of ovarian cancer. Br J Obstet Gynaecol. 1990;97:9229.

7. Timmerman D, Schwärzler P, Collins WP, Claerhout F, Coenen M, Amant F, et al. Subjective assessment of adnexal masses with the use of ultrasonography: an analysis of inter observer variability and experience. Ultrasound Obstet Gynecol. 1999;13:116.

8. Van Holsbeke C, Van Calster B, Valentin L, Testa AC, Ferrazzi E, Dimou I, et al. External validation of mathematical models to distinguish between benign and malignant adnexal tumors: a multicenter study by the International Ovarian Tumor Analysis Group. Clin Cancer Res. 2007;13:4440-7.

9. Timmerman D, Valentin L, Bourne TH, Collins WP, Verrelst H, Vergote I. Terms, definitions and measurements to describe the sonographic features of adnexal tumors: a consensus opinion from the 
International Ovarian Tumor Analysis (IOTA) Group. Ultrasound Obstet Gynecol. 2000:16:500-5.

10. Van nagell JR, DePriest PD. Management of adnexal masses in postmenopausal women. American J Obstetr Gynecol. 2005;193:30-5.

11. American Cancer Society, Cancer facts and figures 2007. Atlanta (GA): ACS; 2007. Available at: http://www.cancer.org/downloads/STT/CAFF2007P WSecured.pdf. Retrieved February 16, 2007.

12. Reis LA, Harkins D, Krapcho M, Mariotto A, Miller BA, Feuer EJ, et al. SEER cancer statistics review,1975-2003. Bethesda (MD): National Cancer Institute; 2006. Available at: http://seer.cancer.gov/csr/1975_2003.Retrieved February 16, 2007.

13. Antonic J, Rakar S. Validity of color and pulsed Doppler US and tumour marker CA 125 in differentiation between benign and malignant ovarian masses. Eur J Gynaecol Oncol. 1996;17:2935.

14. Alcazar JL, Errasti T, Zornoza A, Minguez JA, Galan MJ. Transvaginal color Doppler ultrasonography and CA-125 in suspicious adnexal masses. Int J Gynaecol Obstet. 1999;66:255-61.

15. Itakura T, Kikkawa F, Kajiyama H, Mitsui T, Kawai M, Mizutani S. Doppler flow and arterial location in ovarian tumors. Int J Gynaecol Obstet. 2003;83:27783.

16. Maggino T, Gadducci A, D’Addario V, Pecorelli S, Lissoni A, Stella M, et al. Prospective multicenter study on CA 125 in postmenopausal pelvic masses. Gynecol Oncol. 1994;54:117-23.

17. Schutter EM, Kenemans P, Sohn C, Kristen P, Crombach G,Westermann R, et al. Diagnostic value of pelvic examination, ultrasound, and serum CA 125 in postmenopausal women with a pelvic mass. An international multicenter study. Cancer. 1994;74:1398-406.

18. Sehouli J, Akdogan Z, Heinze T, Konsgen D, Stengel D, Mustea A, et al. Preoperative determination of CASA (Cancer Associated Serum Antigen) and CA-125 for the discrimination between benign and malignant pelvic tumor mass: a prospective study. Anticancer Res. 2003;23:1115-8.

19. Buckshee K, Temsu I, Bhatla N, Deka D. Pelvic examination, transvaginal ultrasound and transvaginal color Doppler sonography as predictors of ovarian cancer. Intern J Gynecol Obstetr. 1998;61(1):51-7.

20. Tailor A, Jurkovic D, Bourne TH, Campbell S. A comparison of intra tumoural indices of blood flow velocity and impedance for the diagnosis of ovarian cancer. Ultrasound Med Biol. 1996;22(7):837-43.

21. Modiseett SC, Pavlik EJ, Ueland FR, DePriest P, Nagell J. Risk of malignancy in unilocular ovarian cystic tumors less than $10 \mathrm{cms}$ in diameter. Obstet Gynaec. 2003;102:594-9.
22. Ueland FR, DePriest PD, Pavlik EJ, Kryscio RJ, van Nagell JR. Preoperative differentiation of malignant from benign ovarian tumors: the efficacy of morphology indexing and Doppler flow sonography. Gynecologic Oncology. 2003;91(1):46-50.

23. Kobal B, Rakar S, Ribic-Pucelj M, Tomazevic T, Zaletel-Kragelj L. Pretreatment evaluation of adnexal tumors predicting ovarian cancer. Int J Gynecol Cancer. 1999;9(6):481-6.

24. Valentin L, Ameye L, Testa A, Lécuru F, Bernard JP, Paladini D et al. Ultrasound characteristics of different types of adnexal malignancies. Gynecologic Oncology. 2006;102(1):41-8.

25. Juhász B, Kurjak A, Lampé L, Hernádi Z. Tissue characterization by transvaginal color Doppler for the evaluation of gynaecological tumours. Acta Med Hung. 1990;47(3-4):135-48.

26. Timor-Tritsch IE, Lerner JP, Monteagudo A, Santos R. Transvaginal ultrasonographic characterization of ovarian masses by means of color flow-directed Doppler measurements and a morphologic scoring system. Amer J Obstet Gynecol. 1993:168(3 Pt 1):909-13.

27. Fleischer AC, Rodgers WH, Rao BK, Kepple DM, Worrell JA, Williams L, et al. Assessment of ovarian tumor vascularity with transvaginal color Doppler sonography. J Ultrasound Med. 1991;10:563-8.

28. Kurjak A, Predanic M. Kupesic-Urek S, Jukic S. Transvaginal color and pulsed Doppler assessment of adnexal tumor vascularity. Gynecol Oncol. 1993;50:3-9.

29. Witczak K, Szpurek D, Moszyński R, Sroka Ł, Sajdak S. Clinical assessment of selected vascularization attributes of adnexal masses in preoperative prediction of tumor malignancy. Ginekol Pol. 2007;78(5):373-7.

30. Madan R, Narula MK, Chitra R, Bajaj P. Sonomorphological and color Doppler flow imaging evaluation of adnexal masses. Ind J Radiol Imag. 2004;14(4):365-72.

31. Fleischer AC, Rodgers WH, Kepple DM, Williams, LL, Jones HW, Gross PR. Color Doppler sonography of benign and malignant ovarian masses. Radiographics. 1992;12(5):879-85.

32. Hamper UM, Sheth S, Abbas FM, Rosenshein NB, Aronson D, Kurman RJ. Transvaginal color Doppler sonography of adnexal masses: differences in blood flow impedance in benign and malignant lesions. AJR Am J Roentgenol. 1993;160(6):1225-8.

33. Marchesini AC, Magrio FA, Berezowski AT, Neto OB, Nogueira AA, Candido dos Reis FJ. A critical analysis of Doppler velocimetry in the differential diagnosis of malignant and benign ovarian masses. J Womens Health (Larchmt). 2008;17(1):97-102.

Cite this article as: Khurana I, Satia MN.

Preoperative evaluation of ovarian masses with color Doppler and its correlation with pathological finding. Int J Reprod Contracept Obstet Gynecol 2016;5: 2084-92. 